\title{
FRACTIONAL INTEGRATION AND ITS INFLUENCE ON UNIT ROOT AND CO-INTEGRATION ANALYSIS
}

\author{
Guilherme de Oliveira lima C. Marques *
}

\begin{abstract}
Este estudo avalia o poder dos testes tradicionais de raízes unitárias e de co-integração, quando aplicados em processos estocásticos fracionariamente integrados no intervalo $0 \leq d \leq 1$. Foram conduzidas simulações de Monte Carlo para avaliar a sensibilidade dos testes de raízes unitárias em distinguir as condições $I(1)-I(0)$ das condições fracionárias. Nossos resultados mostraram que os testes possuem individualmente baixo poder quando aplicados em séries pequenas com memória longa. No entanto, percebemos que sob determinadas condições os testes de raízes unitárias podem apresentar resultados que podem ajudar a evitar o problema da super-diferenciação na análise de estacionariedade das séries. $\mathrm{Na}$ análise de co-integração, considerando alternativas fracionárias no intervalo $0 \leq d \leq 0.6$, encontramos condições que podem conduzir a resultados satisfatórios.
\end{abstract}

Keywords: Teste de raiz unitária, integração fracionária, memória longa, co-integração, simulações de Monte Carlo.

\begin{abstract}
This study assesses the power of traditional unit root and co-integration tests when they are applied to fractionally integrated stochastic processes in the $0 \leq d \leq 1$ range. Monte Carlo simulations were conducted to evaluate the sensitivity of the unit root tests in distinguishing the $I(1)-I(0)$ conditions of the fractional conditions. Our results showed that unit root tests have individually low power when applied to small sample series with long-memory. However, we found that under specific conditions the unit root tests can produce results that can help avoid the over-differentiation problem. In the co-integration analysis for fractional alternatives on the interval $0 \leq d \leq 0.6$, we found some conditions that can lead to satisfactory results.
\end{abstract}

Keywords: Unit root tests, fractional integration, long-memory, co-integration, Monte Carlo simulations

JEL classification: C15, C22, C32

DOI: http://dx.doi.org/10.11606/1413-8050/ea149593

\footnotetext{
*Universidade Federal do ABC. E-mail: guilherme.lima@ufabc.edu.br
} 


\section{Introduction}

Unit root and co-integration tests are widely used in econometric analysis. These kinds of tests are traditionally constructed under the $I(1)-I(0)$ dichotomy, representing, first order integrated series and covariance stationary series, respectively. The $I(1)-I(0)$ paradigm is the basis, for example, of the ARIMA time series models and the co-integration analysis proposed by Engle \& Granger (1987) and Johansen (1995). The best known unit root tests are: The Dickey-Fuller Test (DF) and the Augmented Dickey-Fuller Test (ADF) proposed, respectively by Dickey \& Fuller (1981) and Said e Dickey (1984); the Dickey-Fuller Generalized Least Squares Test (DF-GLS) and the ElliotRothenberg-Stock test (ERS), both introduced in Elliot et al. (1996), and the KPSS Test suggested by Kwiatkowski et al (1992).

With the advent of fractional integration theory for stochastic processes, the conditions established by the $I(1)-I(0)$ paradigm become specific cases of the extended $I(d), d \in \mathbb{R}$. The parameter $d$ is called the fractional integration parameter and is also known as the "long-memory parameter." These models have shown that the effects of past shocks do not remain in the series' memory permanently, but rather transitorily, for long periods.

Unit root tests are mainly concerned with the particular case $d=1$ vs $d=0$, while long-memory models typically focus on $0<d<1$. Unit root $(d=1)$ is a singular mathematical condition that has important economic implications according to Econometric Theory. The unit root economic time series exhibit the "persistence" behavior or "unit root hysteresis" described as permanent effects arising from a temporary stimulus ${ }^{1}$. The persistence issue has been explored in many macroeconomic areas, such as unemployment, exchange rates, business cycles, permanent income theory, purchasing power parity, inflation, etc. Seminal references in these areas are: Nelson \& Plosser (1982), Blanchard \& Summers (1986), Ball \& Mankiw (2002), Campbell \& Mankiw (1987b,a), Baillie \& Bollerslev (1994), and others.

Applied economics research has increasingly been based on the fractional integration paradigm due to its greater versatility in comparison with the $I(1)-I(0)$ paradigm. Diebold \& Rudebusch (1991), for example, sought to identify the persistence of economic shocks on U.S. gross domestic product and unemployment. The study provided evidence in favor of fractional integration orders consistent with persistent mean reversible behavior in series. Caporale \& Gil-Alana (2004) investigated cointegration by analyzing the longmemory dynamics between unemployment, oil prices and interest rates in Canada. Gil-Alana \& Henry (2003) analyzed the relationship between the same variables and the terms of trade in the U.K. with impulse-response functions. Shimotsu (2010) analyzed the data used by Nelson \& Plosser (op. cit) and found that the point estimates of the U.S. unemployment rate are meanreversible. The long-memory behavior of unemployment rates in Brazil and Latin American countries was studied by Gomes \& Gomes da Silva (2009), Marques \& Fava (2011) and Ayala et al. (2012). Fava \& Alves (1998), Reisen et al. (2003) and Figueiredo \& Marques (2011) analyzed Brazilian inflation rate series using ARFIMA Models. Caporale \& Gil-Alana (2004) investigated the Real Business Cycle doctrine based on monthly hours worked in the U.S.

\footnotetext{
${ }^{1}$ The term "unit root hysteresis" was used in order to differentiate it from the original concept proposed in Physics. Other hysteresis concepts applied to Economics are described in Franz (1990) and Gocke (2002).
} 
using Gegenbauer long-memory processes. Other important references will be cited throughout this paper.

Although traditional unit root tests have been built on the $I(1)-I(0)$ paradigm, they can be powerful enough to distinguish the asymptotic stationary and nonstationary mean-reversion conditions defined in the fractional integration framework. This study proposes an evaluation of the properties of traditional unit root tests within the scope of long-memory processes. We analyze, through Monte Carlo simulations, the rejection rate of the unit root hypothesis when the process is fractionally integrated in the $0 \leq d \leq 1$ range. We have paid special attention to simulation results near the asymptotic stationary limit, $d=1 / 2$, to verify if these tests are able to distinguish asymptotic stationary and nonstationary conditions in order to indicate if the series was due to a long-memory process or not. The behavior of the tests was then evaluated on two intervals: $0 \leq d<1 / 2$ and $1 / 2<d \leq 1$.

Another important issue considered in this study is the power of the unit root tests to distinguish the case $1 / 2 \leq d<1$ from $d=1$ in the co-integration perspective. As indicated by Cheung \& Lai (1993) and Caporale \& Gil-Alana (2004), if the residual series of the co-integration model is integrated in the range, although nonstationary, it will still indicate the existence of co-integration in the fractional integration framework. We provide Monte Carlo evidence based on ADF and PP using simulated bivariate fractional co-integrated systems. The simulation analysis proposed allows identification of how unit root tests behave in the nonstationary interval as $d \rightarrow 1$ using the Phillips \& Ouliaris (1990) distribution. We also expanded this analysis by exploring the relative performance of the Johansen (1995) methodology compared to the residual-based tests in the co-integration framework.

Previous research has demonstrated the importance of the subjects addressed in this study. Sowell (1990), for example, derived the asymptotic distribution from the DF test for nonstationary processes and demonstrated its low power. Diebold \& Rudebusch (1991) extended the scope of Sowell's study, performing a Monte Carlo experiment on stationary and nonstationary longmemory processes. They also concluded that the DF test had a low power, increasing as the sample size increased. In another study, Hassler \& Wolters (1994) carried out experiments similar to those of Diebold e Rudebusch, using the "augmented" version of DF test with different lag lengths along with the PP test. The authors demonstrated a high power for the DF and PP tests in the asymptotic stationary interval, higher than that of the ADF test, which suffered negative influences as time lags increased. Lee \& Schmidt (1996) studied the behavior of the KPSS test in series with long-memory and demonstrated its consistency in the stationary interval $|d|<1 / 2$. In general, all of these studies focus on the reduced power of specific unit root tests in evaluating the $I(d)$ condition. However, they disregard the possibility of using some tests together. This is the strategy adopted in this study in order to show how to better identify the stationary and nonstationary mean-reversion conditions.

The remainder of this paper is organized as follows: Section 2 introduces some mathematical concepts related to fractional integration and long-memory processes. Section 3 describes a simulation analysis on the power of traditional unit root tests to correctly identify stationary-nonstationary conditions; Section 4 addresses the influence of long memory in residual-based methods for co-integration analysis; Section 5 is dedicated to the same problem involving Johansen's co-integration analysis, and finally Section 6 discusses some 
conclusions from the study.

\section{Review of Fractional Integration and Long-Memory}

Long-memory processes are characterized by a pole in their spectral density function at zero frequency, $\lim _{\lambda \rightarrow 0} f(\lambda)=+\infty$. Generally, though often imperceptible in graphical terms, long-memory processes are limited in their field of variation and can exhibit locally persistent trends. Integrated processes with $d=1$, or $I(1)$ for short, are known as unit root processes. The $I(1)$ processes represent a particular case of the general mathematical conception of martingales. When $d \geq 1$, the processes are nonstationary and not meanreverting. Applying suitable $d \in \mathbb{Z}$ differences on $d \geq 1$ integrated processes can transform them into long-memory processes. Processes with $1 / 2<d<3 / 2$, for example, have asymptotic stationary increments and will be asymptotically stationary in first differences.

In the early 1980s, Granger \& Joyeux (1980) and Hosking (1981) independently and almost simultaneously introduced the auto-regressive fractionallyintegrated moving-average model, $\operatorname{ARFIMA}(p, d, q), d \in \mathbb{R}$, whose spectral properties reflect the typical shape of economic variables identified by Granger (1966). This class of parametric models is able to describe both long-memory properties and any remaining short-term structure in time series. A process $\left\{y_{t}\right\}_{t \in \mathbb{Z}}$ is defined to be an $\operatorname{ARFIMA}(p, d, q)$ model if it represents a solution of

$$
\Phi(B)(1-B)^{d}\left(y_{t}-\mu\right)=\Theta(B) \epsilon_{t} .
$$

$E\left(y_{t}\right)=\mu$, where $B$ represents the lag operator, $\Phi(B)=1-\phi_{1} B^{1}-\cdots-\phi_{p} B^{p}$ and $\Theta(B)=1+\theta_{1} B^{1}+\cdots+\theta_{q} B^{q}$ are, respectively, the auto-regressive and the moving-average polynomials of orders $p$ and $q$, whose characteristic roots $\Phi(B)=0$ and $\Theta(B)=0$ lie outside the unit circle and $\epsilon_{t \in \mathbb{Z}}$ is a white noise process. The component $(1-B)^{d}$ represents the fractional difference operator which, through the gamma function, $\Gamma(u)=\int_{0}^{+\infty} e^{-t} t^{u-1} d t$, promotes the expansion:

$$
1-B^{d}=\sum_{j=0}^{+\infty} \frac{\Gamma(j-d)}{\Gamma(-d) \Gamma(j+1)} B_{j}, d \in \mathbb{R} .
$$

According to Hosking (1981), an process is asymptotically stationary if $d<1 / 2$, although its autocovariance function decays hyperbolically to zero, $\lim _{h \rightarrow \pm \infty} h^{\alpha} y(h)=c_{h}$, with $c_{h}>0,0<\alpha<1$. ARFIMA processes with $d>$ $-1 / 2$ are invertible, implying that they can be represented in an infinite, autoregressive form. Therefore, ARFIMA processes whose fractional parameter lies in the interval $-1 / 2<d<1 / 2$ are stationary and invertible. Fractionally integrated processes with $1 / 2 \leq d<1$ are nonstationary, but they exhibit the mean-reversion pattern. Cases where $0<d<1$ are traditionally called long-range processes. When $d<0$, however, the processes are called "antipersistent." Anti-persistent processes are marked by a negative, long-range correlation between their increments.

Identifying the power of the unit root tests on the interval $1 / 2 \leq d<1$ is of great importance for econometric analysis. Taking an integer difference of these series results in "over-differentiation," generating noninvertible series from invertible ones. This mistake can, for example, increase the variance of 
filtered series and can result in the estimation of spurious parameters. For $0<$ $d \leq 1 / 2$, we investigate the ability of the tests to correctly indicate the necessity of unit differentiation of the series to make it stationary on the interval $-1 / 2<$ $d \leq 0$.

\section{Simulation Analysis}

The simulation analysis was based on simple, persistent fractional processes in the Fractional Gaussian Noise class,

$$
(1-B)^{d} y_{t}=\epsilon_{t}, \epsilon_{t} \sim N(0,1) .
$$

We compare the results for Fractional Noise with $0<d<1$ and the classical cases $d=0$ and $d=1$ represented, by Gaussian and unit-integrated Gaussian processes, respectively. Deterministic components, such as linear trends or short memory structure terms, were not included in the simulated processes ${ }^{2}$. Anti-persistent processes, $d<0$, were excluded from the studies involving unit root and co-integration tests because they are not common in economic analyses.

Initially, ADF, DF-GLS and ERS tests that are pivotal under the null hypothesis $H_{0}: d=1$ were evaluated. The KPSS test, which is pivotal under the null $H_{0}: d=0$ was evaluated separately. The rejection of $H_{0}: d=1$ for the ADF, DF-GLS and ERS tests, for the fractional cases, implies $d<1$. Thus, our experiment allows us to consider two types of analyses: a "strict" analysis that evaluates the condition $H_{0}: d=1$ vs. $H_{a}: d<1$ and a "broad" analysis that evaluates the power of these tests to detect asymptotic stationary and nonstationary mean-reversible conditions. One may analyze, for example, the hypotheses $H_{0}: d=1$ vs. $H_{a}: 0 \leq d<1 / 2$ and $H_{0}: 1 / 2 \leq d \leq 1$ vs. $H_{a}: 0 \leq d<1 / 2$. The latter case is that in which the researcher would need to determine if the series needs to be differentiated in order to become asymptotic stationary, that is, inside the fractional integration scope. In this case the non-rejection of $H_{0}$ when it is false (type II error) leads to the application of an integer difference on the series that will produce noninvertible processes, $d<-1 / 2$.

The procedure adopted in the simulations was to identify the percentage of rejections of the unit root null hypothesis, when the process is constructed in such a way that $0 \leq d \leq 1$, thus covering all possibilities foreseen in the broad and strict analyses. The number of lags used in the auto-regressive structure of all tests except PP was chosen based on the criteria defined by $\mathrm{Ng}$ \& Perron (1995), with a maximum of 12 lags. This maximum number of lags was chosen based on the traditional procedures for short-memory processes and suggested as a default by many econometric software packages. Even for long-memory processes, the Ng-Perron criteria hardly exceed the number of 12 lags implemented in our simulations. In the PP test the number of lags is set to one. The computer simulation routines were written in the $\mathrm{S}$ and $\mathrm{R}$ languages, using Finmetrics 2.02 module code. For each value in $0 \leq$ $d \leq 1$, with intervals of $\delta=0.10, M=1000$ simulated processes with sizes typical of economic time series were generated: $N=100,200,300,1000$. Each unit root test was applied to the $M$ simulated processes and the null rejection proportions were calculated.

\footnotetext{
${ }^{2}$ Definitions of Gaussian fractional processes are found in Beran (1994).
} 
The nonstationary, mean-reversion processes, $1 / 2<d<1$, were generated by applying the accumulated sum to anti-persistent processes with $-1 / 2<$ $d<0$. The unit root processes, $d=1$, were generated by applying the accumulated sum to Gaussian white noise processes. The specific point $d=1 / 2$ that represents the threshold between asymptotic stationary and nonstationary conditions was not evaluated in this study due to its high instability in the simulation procedures.

Table 1 shows the percentage of rejections of the unit root null hypothesis for the ADF, DF-GLS, ERS and KPSS tests with 1\%, 5\% and 10\% significance levels. For $d=0$ or $d=1$, the tests were well-behaved with the significance levels adopted. As might be expected, the rate of rejection of the null $H_{0}: d=1$ for the ADF, DF-GLS and ERS tests decreased as the process integration order moved away from the zero. The rate decreased more quickly in the range defining nonstationary mean-reversible processes than in the range defining asymptotic stationary processes. The opposite was observed when using the KPSS test. The power of the tests clearly depends on the sample size. Therefore, in the strict analysis, the pivotal tests around $H_{0}: d=1$ have low power against the fractional condition $H_{a}: d<1$. This fact may be deduced by the high rate of non-rejection of $H_{0}$ in the $1 / 2 \leq d<1$ range. The values in Table 1 for $0 \leq d<1 / 2$ represent the percentage rejection of $H_{0}: d=1$, when $H_{0}$ is false in the broad analysis, which defines the power of tests for asymptotic stationarity ${ }^{3}$

For large samples, the rate of rejection of $H_{0}$ in the ADF and DF-GLS tests was close to $100 \%$ in the asymptotic stationary range. For series with 300 , 200 and 100 observations, the $H_{0}$ rejection percentage decreases significantly, indicating the low power of the tests to detect asymptotic stationarity in small samples. As approaches to the asymptotic stationarity threshold $d=0,5$ (the closest point evaluated in this study was $d=0,4$ ), the tests ADF, DF-GLS and ERS rejected $H_{0}: d=1$, with a significance level of $5 \%$ and $N=100$ only in $33.0 \%, 37.0 \%$ and $19.2 \%$ of the cases, respectively. In series with sample size $N=200$, the percentage rises to $64.1 \%, 59.8 \%$ and $34.3 \%$ respectively. For large samples, $N=1000$, the percentage of rejection was high: $99.5 \%, 99.5 \%$ and $93.1 \%$. This results shows that the tests are not powerful when series are asymptotic stationary.

For series sizes typical of macroeconomic research series sizes (except financial series), $N \leq 300$, the tests do not clearly distinguish the asymptotic stationary condition. The rate of rejections of $H_{0}: d=1$ when $1 / 2<d \leq 1$ is similar for the three tests. For series with $N=1000$ and integrated order $d=0,7$, for example, the ADF, DF-GLS and ERS tests reject the null hypothesis under the $5 \%$ significance level for only $54.1 \%, 47.5 \%$ and $53.8 \%$ of cases, respectively. The percentage is even lower for series with fewer observations, or as $d \rightarrow 1$. With $N=100$ samples and $d=0,7$, the ADF test rejected the null hypothesis of the unit root level with a 5\% significance level in $15.8 \%$ of the cases, and the DF-GLS and ERS tests rejected it in $18.5 \%$ and $18.1 \%$ of cases, respectively. For $d=0,8$, the proportions found are $13.7 \%, 13.0 \%$ and $13.0 \%$. The level of non rejection of the null hypothesis $H_{0}: d=1$ in the range $1 / 2 \leq d<1$ reflects the low power of tests to distinguish series with a unit root

\footnotetext{
${ }^{3}$ Although the null hypothesis is specific for $d=1$, the ability of the tests to detect the nonstationarity of series in the $1 / 2<d \leq 1$ interval can be evaluated. In this case, the values presented in the table $11 / 2<d \leq 1$ represent the proportion of rejections of $H_{0}$ : nonstationary series when is true. The levels shown in the table reveal the low power of tests for this case.
} 
Table 1: Percentage of Rejections of the Unit Root Hypothesis for Long-Memory $(\mathrm{M}=1000)$

\begin{tabular}{|c|c|c|c|c|c|c|c|c|c|c|c|c|c|}
\hline & \multicolumn{3}{|c|}{$A D F^{\dagger}$} & \multicolumn{4}{|c|}{$D F-G L S^{\dagger}$} & \multicolumn{3}{|c|}{$E R S^{\dagger}$} & \multicolumn{3}{|c|}{ KPSS } \\
\hline & $\mathrm{N}$ & $1 \%$ & $5 \%$ & $10 \%$ & $1 \%$ & $5 \%$ & $10 \%$ & $1 \%$ & $5 \%$ & $10 \%$ & $1 \%$ & $5 \%$ & $10 \%$ \\
\hline \multirow{4}{*}{$d=0.0$} & 100 & 68.3 & 88.0 & 95.6 & 67.4 & 84.6 & 95.6 & 48.6 & 61.2 & 68.4 & 0.4 & 3.3 & 9.0 \\
\hline & 200 & 98.5 & 100 & 100 & 98.9 & 100 & 100 & 65.8 & 81.1 & 86.9 & 0.5 & 4.0 & 9.1 \\
\hline & 300 & 100 & 100 & 100 & 100 & 100 & 100 & 85.6 & 94.2 & 97.5 & 1.1 & 5.7 & 10.3 \\
\hline & 1000 & 100 & 100 & 100 & 100 & 100 & 100 & 99.7 & 100 & 100 & 1.3 & 4.7 & 8.6 \\
\hline \multirow{4}{*}{$d=0.1$} & 100 & 52.9 & 76.1 & 90.6 & 53.0 & 76.2 & 88.1 & 30.6 & 41.6 & 50.0 & 2.4 & 10.2 & 17.3 \\
\hline & 200 & 94.2 & 99.5 & 100 & 95.3 & 99.4 & 100 & 50.6 & 69.5 & 80.6 & 4.5 & 12.5 & 23.2 \\
\hline & 300 & 99.8 & 100 & 100 & 100 & 100 & 100 & 71.7 & 85.5 & 93.1 & 4.4 & 13.7 & 22.2 \\
\hline & 1000 & 100 & 100 & 100 & 100 & 100 & 100 & 98.9 & 99.9 & 100 & 7.6 & 17.9 & 26.3 \\
\hline \multirow{4}{*}{$d=0.2$} & 100 & 35.9 & 60.4 & 77.6 & 39.7 & 63.3 & 78.5 & 21.0 & 33.2 & 41.7 & 5.1 & 18.7 & 28.7 \\
\hline & 200 & 79.4 & 96.6 & 99.1 & 79.7 & 97.3 & 99.5 & 36.3 & 56.8 & 70.6 & 10.7 & 26.1 & 36.9 \\
\hline & 300 & 97.9 & 100 & 100 & 97.7 & 99.9 & 100 & 56.8 & 78.4 & 86.9 & 14.7 & 29.5 & 40.1 \\
\hline & 1000 & 100 & 100 & 100 & 100 & 100 & 100 & 96.2 & 98.8 & 99.7 & 21.5 & 41.9 & 53.0 \\
\hline \multirow{4}{*}{$d=0.3$} & 100 & 24.6 & 49.7 & 68.1 & 23.9 & 46.9 & 63.4 & 12.2 & 23.9 & 36.3 & 12.7 & 32.0 & 43.4 \\
\hline & 200 & 79.4 & 96.6 & 99.1 & 79.7 & 97.3 & 99.5 & 36.3 & 56.8 & 70.6 & 10.7 & 26.1 & 36.9 \\
\hline & 300 & 97.9 & 100 & 100 & 97.7 & 99.9 & 100 & 56.8 & 78.4 & 86.9 & 14.7 & 29.5 & 40.1 \\
\hline & 1000 & 100 & 100 & 100 & 100 & 100 & 100 & 96.2 & 98.8 & 99.7 & 21.5 & 41.9 & 53.0 \\
\hline \multirow{4}{*}{$d=0.4$} & 100 & 15.2 & 33.0 & 51.2 & 15.7 & 37.0 & 53.2 & 5.3 & 19.2 & 32.8 & 19.3 & 35.5 & 49.5 \\
\hline & 200 & 31.6 & 64.1 & 79.5 & 31.0 & 59.8 & 74.4 & 14.2 & 34.3 & 51.9 & 34.8 & 55.0 & 66.2 \\
\hline & 300 & 48.0 & 76.3 & 87.7 & 50.2 & 77.9 & 87.7 & 23.8 & 52.4 & 68.5 & 41.6 & 60.3 & 70.0 \\
\hline & 1000 & 96.0 & 99.5 & 99.9 & 96.2 & 99.5 & 99.9 & 79.6 & 93.1 & 96.5 & 62.1 & 79.8 & 88.1 \\
\hline \multirow{4}{*}{$d=0.6$} & 100 & 7.4 & 19.6 & 30.1 & 6.6 & 18.8 & 32.0 & 7.2 & 21.7 & 33.2 & 39.9 & 56.5 & 68.1 \\
\hline & 200 & 10.5 & 32.5 & 48.6 & 10.2 & 30.8 & 47.6 & 11.6 & 31.4 & 45.9 & 57.9 & 76.8 & 85.1 \\
\hline & 300 & 17.4 & 43.1 & 58.4 & 18.6 & 42.5 & 55.8 & 16.3 & 40.4 & 57.2 & 61.3 & 79.6 & 87.6 \\
\hline & 1000 & 50.4 & 71.8 & 83.3 & 50.0 & 70.0 & 81.5 & 50.2 & 71.3 & 82.9 & 88.4 & 95.8 & 98.3 \\
\hline \multirow{4}{*}{$d=0.7$} & 100 & 4.7 & 15.8 & 28.9 & 6.4 & 18.5 & 29.2 & 4.1 & 18.1 & 32.5 & 45.4 & 65.4 & 74.7 \\
\hline & 200 & 7.4 & 24.5 & 38.8 & 11.4 & 28.5 & 39.4 & 8.1 & 23.9 & 38.3 & 66.5 & 84.4 & 90.6 \\
\hline & 300 & 11.9 & 30.8 & 45.0 & 12.3 & 31.8 & 44.6 & 12.2 & 32.4 & 48.4 & 72.8 & 86.3 & 91.7 \\
\hline & 1000 & 31.4 & 54.1 & 68.1 & 26.1 & 47.3 & 61.4 & 31.7 & 53.8 & 67.3 & 91.9 & 96.8 & 98.5 \\
\hline \multirow{4}{*}{$d=0.8$} & 100 & 3.7 & 13.7 & 21.5 & 2.7 & 13.0 & 24.8 & 1.6 & 13.1 & 23.8 & 55.0 & 72.0 & 81.7 \\
\hline & 200 & 4.8 & 18.7 & 30.4 & 5.6 & 19.2 & 28.5 & 4.6 & 18.5 & 32.1 & 75.7 & 87.9 & 93.8 \\
\hline & 300 & 7.0 & 19.8 & 33.0 & 6.5 & 20.8 & 32.0 & 7.9 & 22.2 & 36.8 & 80.8 & 92.0 & 96.3 \\
\hline & 1000 & 14.8 & 32.7 & 45.9 & 12.9 & 32.5 & 44.4 & 13.2 & 31.3 & 46.1 & 96.4 & 99.3 & 99.8 \\
\hline \multirow{4}{*}{$d=0.9$} & 100 & 1.3 & 9.3 & 17.9 & 2.5 & 9.1 & 17.3 & 1.0 & 9.0 & 16.9 & 63.8 & 80.8 & 87.8 \\
\hline & 200 & 2.1 & 9.0 & 18.2 & 3.2 & 11.4 & 21.1 & 2.4 & 8.7 & 17.0 & 80.3 & 90.8 & 94.7 \\
\hline & 300 & 3.6 & 11.4 & 20.3 & 3.2 & 12.9 & 23.0 & 3.6 & 12.8 & 22.7 & 86.2 & 94.9 & 97.3 \\
\hline & 1000 & 5.2 & 15.9 & 26.1 & 3.9 & 14.7 & 23.6 & 5.2 & 16.3 & 25.8 & 98.0 & 99.8 & 99.9 \\
\hline \multirow{4}{*}{$d=1.0$} & 100 & 0.5 & 4.0 & 7.4 & 0.5 & 3.3 & 8.4 & 0.5 & 3.2 & 8.6 & 71.3 & 84.5 & 90.3 \\
\hline & 200 & 0.8 & 3.9 & 11.0 & 0.8 & 4.9 & 9.9 & 0.4 & 4.1 & 9.7 & 86.5 & 95.6 & 97.5 \\
\hline & 300 & 1.1 & 4.8 & 8.6 & 1.1 & 6.0 & 10.0 & 0.9 & 5.5 & 10.6 & 91.6 & 97.5 & 98.9 \\
\hline & 1000 & 1.3 & 3.6 & 7.8 & 1.3 & 7.3 & 11.2 & 0.9 & 4.5 & 10.5 & 99.3 & 99.7 & 99.8 \\
\hline
\end{tabular}

\footnotetext{
${ }^{\dagger} H_{0}: d=1$
}

$\ddagger H_{0}: d=0$ 
from those that are nonstationary with mean-reversion. Such imprecision can reflect the low power of co-integration tests of Engle e Granger's type when the model's residuals are fractionally integrated in the $1 / 2 \leq d<1$ range. This topic will be discussed further in the next section. The analysis based on the KPSS test is particularly distinct. Due to its construction, the KPSS test is pivotal around $H_{0}: d=0$, meaning a "covariance stationary series." Therefore, the inference for this test is the opposite of that of the three tests evaluated earlier. Figure 1 shows the null hypothesis rejection index curves for simulated series with sample sizes $N=100,200,300,1000$.

For simulated fractionally integrated series the KPSS test showed low levels of rejection of $H_{0}: d=0$ for $0<d<1 / 2$, revealing the low power of the test in the strict sense, that is, for $H_{0}: d=0$ versus $H_{0}: d>0$. For example, with $d=0,3$ and and $N=200$ a significance level of $5 \%$, the KPSS rejects $H_{0}: d=0$ in only $38.7 \%$ of cases. For large integrated series with $1 / 2 \leq d<1$, the KPSS test shows satisfactory power. For $d=0,7$ and $N=1000$, the test rejected $H_{0}$ in $96.8 \%$ of cases. For the same sample size, simulations with $d=0,8$ and $d=0,9$ rejected $H_{0}$ in $93.3 \%$ of the cases and $99.8 \%$ of the cases. That is, the KPSS test is able to identify the condition $H_{0}: d=0$ vs. $H_{a}: 1 / 2 \leq d \leq 1$, which represents its ability to identify the nonstationary (mean-reversible or not) condition in time series.

If one is interested in evaluating the need to apply an integer difference on the series to make it stationary and invertible, that is, inside the $-1 / 2<d<$ $1 / 2$ interval, the results of this study show that, if large series are available, such as $N \geq 1000$, one can use the results of the ADF and KPSS tests. Table 2 summarizes the proportion of hits using these two tests in the simulation experiment at the $5 \%$ significance level. It is interesting to note that the best test depends on both the sample size and the integration order. For example, for series with $N=100$ samples on the asymptotic stationarity interval, the KPSS test is more powerful than the ADF test. For the same sample size, the ADF test is better on the nonstationary interval. As the sample size increases, the ADF and KPSS tests change their positions: the ADF test becomes more accurate than the KPSS test in identifying the stationary condition and the KPSS test is more accurate than the ADF test in the nonstationary interval. For $N=1000$, both tests together result in a significance level higher than $5 \%$ for all integration orders. For series with a reasonable sample size satisfying the fractional integration condition, if the ADF test indicates that series is stationary and KPSS does not, our results reveal that ADF is preferable and one should not apply an ordinary difference on the series. However, if KPSS indicates that a series is not stationary and ADF indicates the contrary, then preference should be given to the KPSS result. If both tests reject their null hypotheses, our results suggests that the ADF result is preferable to the KPSS because the power of ADF is higher on the interval $0 \leq d<1 / 2$ than the power of KPSS on the $1 / 2 \leq d \leq 1$ interval.

\section{Evaluating the Power of Residual-based Co-integration Tests Under Fractional Integration}

The previous results lead to another important question in econometrics: what are the implications of the low power of unit root tests under fractional integration conditions for co-integration analysis? The residual-based test pro- 
Table 2: Proportion of Hits of the Need to Apply or Not an Integer Difference

\begin{tabular}{|c|c|c|c|c|c|c|c|c|c|c|c|c|c|}
\hline \multirow{2}{*}{ Condition } & \multirow{2}{*}{$d$} & \multicolumn{3}{|c|}{$N=100$} & \multicolumn{3}{|c|}{$N=200$} & \multicolumn{3}{|c|}{$N=300$} & \multicolumn{3}{|c|}{$N=1000$} \\
\hline & & $\begin{array}{c}\text { ADF (\%) } \\
\text { Hits }\end{array}$ & $\begin{array}{c}\text { KPSS (\%) } \\
\text { Hits }\end{array}$ & Best & $\begin{array}{c}\text { ADF (\%) } \\
\text { Hits }\end{array}$ & $\begin{array}{c}\text { KPSS (\%) } \\
\text { Hits }\end{array}$ & Best & $\begin{array}{c}\text { ADF (\%) } \\
\text { Hits }\end{array}$ & $\begin{array}{c}\text { KPSS (\%) } \\
\text { Hits }\end{array}$ & Best & $\begin{array}{c}\text { ADF (\%) } \\
\text { Hits }\end{array}$ & $\begin{array}{c}\text { KPSS (\%) } \\
\text { Hits }\end{array}$ & Best \\
\hline \multirow{5}{*}{ Asymptotic Stationary } & 0.0 & 88.0 & 96.7 & KPSS & 100 & 96.0 & ADF & 100 & 94.3 & ADF & 100 & 95.3 & ADF \\
\hline & 0.1 & 76.1 & 89.8 & KPSS & 99.5 & 87.5 & $\mathrm{ADF}$ & 100 & 86.3 & $\mathrm{ADF}$ & 100 & 82.1 & ADF \\
\hline & 0.2 & 60.4 & 81.3 & KPSS & 96.6 & 73.9 & $\mathrm{ADF}$ & 100 & 70.5 & $\mathrm{ADF}$ & 100 & 58.1 & ADF \\
\hline & 0.3 & 49.7 & 68.0 & KPSS & 85.0 & 61.3 & $\mathrm{ADF}$ & 96.4 & 54.0 & $\mathrm{ADF}$ & 100 & 38.2 & $\mathrm{ADF}$ \\
\hline & 0.4 & 33.0 & 64.5 & KPSS & 64.1 & 45.0 & $\mathrm{ADF}$ & 76.3 & 39.7 & $\mathrm{ADF}$ & 99.5 & 20.2 & $\mathrm{ADF}$ \\
\hline \multirow{4}{*}{ Nonstationary Mean-Reversible } & 0.6 & 80.4 & 56.5 & $\mathrm{ADF}$ & 67.5 & 76.8 & KPSS & 56.9 & 79.6 & KPSS & 28.2 & 95.8 & KPSS \\
\hline & 0.7 & 84.2 & 65.4 & $\mathrm{ADF}$ & 75.5 & 84.4 & KPSS & 69.2 & 86.3 & $\mathrm{ADF}$ & 45.9 & 96.8 & KPSS \\
\hline & 0.8 & 86.3 & 72.0 & $\mathrm{ADF}$ & 81.3 & 87.9 & KPSS & 80.2 & 92.0 & KPSS & 67.3 & 99.3 & KPSS \\
\hline & 0.9 & 90.7 & 80.8 & $\mathrm{ADF}$ & 91.0 & 90.8 & $\mathrm{ADF}$ & 88.6 & 94.9 & KPSS & 84.1 & 99.8 & KPSS \\
\hline $\mathrm{I}(\mathbf{1})$ & 1.0 & 96.0 & 84.5 & ADF & 96.1 & 95.6 & ADF & 95.2 & 97.5 & KPSS & 96.4 & 99.7 & KPSS \\
\hline
\end{tabular}




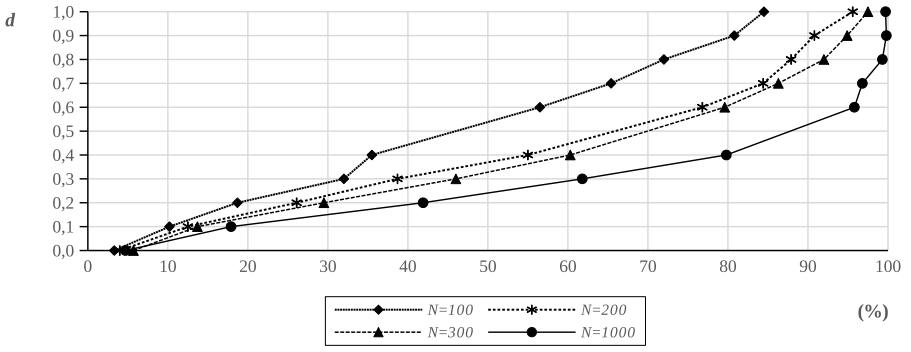

Figure 1: Percentage of Rejections of Null Hypothesis by the KPSS (5\% Significance Level)

posed by Engle \& Granger (1987) is traditionally calculated using the ADF and PP tests to infer a long-term relationship between two variables. Kramer (1998) and Kramer \& Marmol (2004) deduced the theoretical behavior rates of divergence of unit root tests when applied to fractional disturbances in co-integration analyses, and showed that these tests tend to have low power when the co-integration error follows a nonstationary mean-reversion process. In order to address this subject empirically, we provide Monte Carlo evidence based on ADF and PP tests under fractional integration using the adjusted Phillips \& Ouliaris (1990) distributions for co-integration analysis.

The notion of fractional co-integration follows the econometric principles introduced by Engle \& Granger (1987) within the scope of the $I(1)-I(0)$ paradigm. According to Caporale \& Gil-Alana (2004), fractional co-integration may be defined as:

Definition 1: The components $x_{i t}$ of a $(N \times 1)$ vector $\mathbf{x}_{t}$ are said to be fractionally co-integrated of order (d.b) with notation $\mathbf{x}_{t} \sim C I(d, b)$, if: (I) all processes $x_{i t}$ are integrated of the same order, $x_{i t} I(d), d \in \mathbb{R}$ and (II) there exists at least one vector $\beta_{i}=0$ in the $N \times r$ ) co-integration matrix $\beta$ such that $\beta \mathbf{x}_{\mathbf{t}} I(d-b)$, with $b>0$

In our simulations, we assumed a simple I(1) bivariate fractionally cointegrated system $x_{t}^{\prime}=\left(X_{1 t}, x_{2 t}\right)^{\prime}$ with normalized co-integration vector, $\beta^{\prime}=$ $\left(1-\beta_{2}\right), \beta_{2} \neq 0$ and one common stochastic trend dictated by the unit root in $x_{2 t}$. Using the triangular representation, the simulated systems may be written as:

$$
\begin{aligned}
(1-B)^{d}\left(x_{1 t}-\beta_{2} x_{2 t}\right) & =\epsilon_{1 t}, \\
(1-B)^{d} x_{2 t} & =\epsilon_{2 t}
\end{aligned}
$$

where $\epsilon_{1 t}, \epsilon_{2 t} \sim N(0,1)$ and $0<d<1$. According to Definition 1 the fractional co-integration may be analyzed on two intervals: as resulting from the stationary invertible long-memory relation, $0<d<1 / 2$, or resulting from a noncovariance stationary mean reversion process, $1 / 2 \leq d<1$.

Phillips \& Ouliaris (1990) showed that the statistical distributions for ADF and PP tests do not follow the usual distributions for ordinary unit root tests when they are applied to traditional co-integration analysis. As described by Zivot \& Wang (2006), the Phillips e Ouliaris distribution depends on the deterministic components present in the series. Following these indications, we 
used the critical values in this study obtained by using the surface-response methodology introduced by MacKinnon (1996).

The procedures are quite similar to the previous analysis performed in this study: we analyzed the percentage of rejections of the null using the adjusted distributions for residual-based co-integration tests. The basic difference is that the analyzed series are the residuals from ordinary least-squares estimates of the model involving two integrated series that are fractionally co-integrated.

For each order in $0 \leq d \leq 1$, with intervals $\delta=0,1$, we generated fractional co-integrated systems with sample sizes $2 N, N=\{100,200,300,1000\}$, and applied the ADF and PP tests to the last $N$ samples of each simulation. This procedure of discarding the first half of the samples was used to reduce the effects of initial conditions. The simulated series $x_{1 t}$ and $x_{2 t}$ were calculated recursively based on $\epsilon_{1 t}$ and $\epsilon_{2 t}$ for a given value $\beta_{2}=2$ and $0 \leq d \leq 1$. No deterministic trends or AR and MA short-memory components were added to the models. Table 3 shows the proportion of rejections of the null hypothesis (no co-integration) obtained using the ADF and PP tests. Once simulated series were generated without constant or deterministic terms, we used the Phillips e Ouliaris distribution with one constant, as indicated by the authors.

The values presented in Table 3 reveal that co-integration analysis based on the ADF Test using the Ng \& Perron (1995) criteria and a maximum of 12 lags has low power for small samples $(N<1000)$ for both intervals $0 \leq d<1 / 2$ and $1 / 2 \leq d<1$.

As expected, the percentage of rejections decreases as $d \rightarrow 1$. By reducing the number of lags in the $\mathrm{Ng}$ e Perron algorithm, the power of the ADF test increased. For a 5\% significance level, for example, simulations of series with $d=0.1$ and $N=100$ and with a maximum of 12 lags rejected the null hypothesis of no co-integration in only $22.6 \%$ of cases. However, with a maximum of 3 lags, the percentage of rejections of no co-integration grew to $100 \%$. As shown in Table 4, for a fixed number of 1 lag the ADF and PP tests have shown good results for the covariance stationary interval even with small samples ${ }^{4}$

With large sample sizes, these tests give similar, good results up to order $d=0.7$. These interesting results with respect to the number of lags in unit root tests are probably due to long-memory effects. The test equations of unit root models are specified in first differences, and the co-integration residuals are fractionally integrated on the interval $0<d<1$. Thus, over-differentiation may produce an anti-persistent process with negative autocorrelations that causes mistakes in identification in the Ng e Perron (1995) procedure.

Following the usual procedures of the $I(1)-I(0)$ co-integration analysis, we found that ADF and PP tests have, in general, low power when applied to small-sample fractionally co-integrated systems. Although this study is based on specific cases of fractional co-integration, we found evidence that under certain conditions the traditional co-integration analysis has reasonable power to detect the common long-term relationship in the asymptotic stationary interval $0<d<1 / 2$. The power of the tests was shown to be strongly influenced by the number of lags chosen, and the long-memory structure may make correct identification in small samples difficult.

\footnotetext{
${ }^{4}$ The mechanics of the PP test is based on just one lag.
} 
Table 3: Percentage of Rejections of no Co-Integration Null Hypothesis - Max. 12 lags

\begin{tabular}{cccccccccccccc}
\hline & $d$ & \multicolumn{3}{c}{$N=100$} & \multicolumn{3}{c}{$N=200$} & \multicolumn{3}{c}{$N=300$} & \multicolumn{3}{c}{$N=1000$} \\
\cline { 2 - 12 } & $1 \%$ & $5 \%$ & $10 \%$ & $1 \%$ & $5 \%$ & $10 \%$ & $1 \%$ & $5 \%$ & $10 \%$ & $1 \%$ & $5 \%$ & $10 \%$ \\
\hline 0.0 & 0.1450 & 0.2780 & 0.4030 & 0.5500 & 0.8610 & 0.9510 & 0.9650 & $\mathbf{0 . 9 9 7 0}$ & 1.0000 & 1.0000 & $\mathbf{1 . 0 0 0 0}$ & 1.0000 \\
$\mathrm{ADF}$ & 0.1 & 0.1120 & 0.2260 & 0.3310 & 0.3790 & 0.7410 & 0.8880 & 0.8350 & $\mathbf{0 . 9 7 8 0}$ & 0.9950 & 1.0000 & $\mathbf{1 . 0 0 0 0}$ & 1.0000 \\
& 0.2 & 0.0840 & 0.1700 & 0.2620 & 0.2310 & 0.5510 & 0.7190 & 0.6350 & 0.9000 & 0.9630 & 1.0000 & $\mathbf{1 . 0 0 0 0}$ & 1.0000 \\
& 0.3 & 0.0750 & 0.1620 & 0.2490 & 0.1600 & 0.4110 & 0.5740 & 0.3740 & 0.7120 & 0.8690 & 1.0000 & $\mathbf{1 . 0 0 0 0}$ & 1.0000 \\
& 0.4 & 0.0390 & 0.1010 & 0.1860 & 0.0830 & 0.2530 & 0.3930 & 0.1900 & 0.4570 & 0.6330 & 1.0000 & $\mathbf{1 . 0 0 0 0}$ & 1.0000 \\
& 0.6 & 0.0170 & 0.0680 & 0.1280 & 0.0290 & 0.1060 & 0.1840 & 0.0550 & 0.1850 & 0.3020 & 0.9990 & $\mathbf{0 . 9 9 9 0}$ & 1.0000 \\
& 0.7 & 0.0060 & 0.0380 & 0.0780 & 0.0170 & 0.0840 & 0.1420 & 0.0330 & 0.1170 & 0.2050 & 0.9140 & $\mathbf{0 . 9 6 4 0}$ & 0.9780 \\
& 0.8 & 0.0030 & 0.0270 & 0.0490 & 0.0020 & 0.0340 & 0.0720 & 0.0100 & 0.0530 & 0.1120 & 0.4160 & 0.6080 & 0.7290 \\
& 0.9 & 0.0010 & 0.0150 & 0.0360 & 0.0040 & 0.0290 & 0.0630 & 0.0090 & 0.0290 & 0.0700 & 0.0380 & 0.1210 & 0.1950 \\
1.0 & 0.0010 & 0.0080 & 0.0270 & 0.0010 & 0.0110 & 0.0270 & 0.0020 & 0.0160 & 0.0410 & 0.0050 & 0.0260 & 0.0440 \\
\hline
\end{tabular}


Table 4: Percentage of Rejections of no Co-Integration Null Hypothesis - 1lag fixed

\begin{tabular}{|c|c|c|c|c|c|c|c|c|c|c|c|c|c|}
\hline & \multirow{2}{*}{$d$} & \multicolumn{3}{|c|}{$N=100$} & \multicolumn{3}{|c|}{$N=200$} & \multicolumn{3}{|c|}{$N=300$} & \multicolumn{3}{|c|}{$N=1000$} \\
\hline & & $1 \%$ & $5 \%$ & $10 \%$ & $1 \%$ & $5 \%$ & $10 \%$ & $1 \%$ & $5 \%$ & $10 \%$ & $1 \%$ & $5 \%$ & $10 \%$ \\
\hline \multirow{10}{*}{ ADF } & 0.0 & 1.0000 & 1.0000 & 1.0000 & 1.0000 & 1.0000 & 1.0000 & 1.0000 & 1.0000 & 1.0000 & 1.0000 & 1.0000 & 1.0000 \\
\hline & 0.1 & 1.0000 & 1.0000 & 1.0000 & 1.0000 & 1.0000 & 1.0000 & 1.0000 & 1.0000 & 1.0000 & 1.0000 & 1.0000 & 1.0000 \\
\hline & 0.2 & 1.0000 & 1.0000 & 1.0000 & 1.0000 & 1.0000 & 1.0000 & 1.0000 & 1.0000 & 1.0000 & 1.0000 & 1.0000 & 1.0000 \\
\hline & 0.3 & 0.9980 & 1.0000 & 1.0000 & 1.0000 & 1.0000 & 1.0000 & 1.0000 & 1.0000 & 1.0000 & 1.0000 & 1.0000 & 1.0000 \\
\hline & 0.4 & 0.9840 & 0.9980 & 0.9990 & 1.0000 & 1.0000 & 1.0000 & 1.0000 & 1.0000 & 1.0000 & 1.0000 & 1.0000 & 1.0000 \\
\hline & 0.6 & 0.4510 & 0.6990 & 0.8190 & 0.8120 & 0.9200 & 0.9570 & 0.9190 & 0.9790 & 0.9930 & 0.9980 & 1.0000 & 1.0000 \\
\hline & 0.7 & 0.1600 & 0.3980 & 0.5300 & 0.4110 & 0.6570 & 0.7550 & 0.5610 & 0.7560 & 0.8380 & 0.9150 & 0.9770 & 0.9850 \\
\hline & 0.8 & 0.0330 & 0.1330 & 0.2370 & 0.0930 & 0.2560 & 0.3610 & 0.1470 & 0.3320 & 0.4350 & 0.4140 & 0.6060 & 0.7070 \\
\hline & 0.9 & 0.0090 & 0.0420 & 0.0820 & 0.0160 & 0.0630 & 0.1110 & 0.0220 & 0.0970 & 0.1640 & 0.0280 & 0.1250 & 0.2110 \\
\hline & 1.0 & 0.0040 & 0.0180 & 0.0370 & 0.0000 & 0.0210 & 0.0460 & 0.0060 & 0.0240 & 0.0440 & 0.0020 & 0.0130 & 0.0310 \\
\hline \multirow{10}{*}{ PP } & 0.0 & 1.0000 & 1.0000 & 1.0000 & 1.0000 & 1.0000 & 1.0000 & 1.0000 & 1.0000 & 1.0000 & 1.0000 & 1.0000 & 1.0000 \\
\hline & 0.1 & 1.0000 & 1.0000 & 1.0000 & 1.0000 & 1.0000 & 1.0000 & 1.0000 & 1.0000 & 1.0000 & 1.0000 & 1.0000 & 1.0000 \\
\hline & 0.2 & 1.0000 & 1.0000 & 1.0000 & 1.0000 & 1.0000 & 1.0000 & 1.0000 & 1.0000 & 1.0000 & 1.0000 & 1.0000 & 1.0000 \\
\hline & 0.3 & 1.0000 & 1.0000 & 1.0000 & 1.0000 & 1.0000 & 1.0000 & 1.0000 & 1.0000 & 1.0000 & 1.0000 & 1.0000 & 1.0000 \\
\hline & 0.4 & 0.9770 & 0.9950 & 0.9990 & 1.0000 & 1.0000 & 1.0000 & 1.0000 & 1.0000 & 1.0000 & 1.0000 & 1.0000 & 1.0000 \\
\hline & 0.6 & 0.3850 & 0.6280 & 0.7340 & 0.6690 & 0.8100 & 0.8790 & 0.8260 & 0.9160 & 0.9460 & 0.9740 & 0.9930 & 0.9970 \\
\hline & 0.7 & 0.1570 & 0.3420 & 0.4530 & 0.2680 & 0.4670 & 0.5770 & 0.3970 & 0.5920 & 0.6860 & 0.7350 & 0.8490 & 0.8930 \\
\hline & 0.8 & 0.0320 & 0.1010 & 0.1920 & 0.0710 & 0.1920 & 0.2740 & 0.0910 & 0.1950 & 0.2970 & 0.2110 & 0.3830 & 0.4750 \\
\hline & 0.9 & 0.0100 & 0.0430 & 0.0800 & 0.0090 & 0.0340 & 0.0820 & 0.0120 & 0.0520 & 0.0960 & 0.0270 & 0.0990 & 0.1620 \\
\hline & 1.0 & 0.0020 & 0.0220 & 0.0400 & 0.0020 & 0.0150 & 0.0330 & 0.0030 & 0.0160 & 0.0430 & 0.0020 & 0.0190 & 0.0410 \\
\hline
\end{tabular}




\section{A comparison Between Johansen's Co-Integration Tests ans Residual-Based Method When Applied to Fractionally Integrated Bivariate Systems}

The relative performance of unit root tests in identifying the $I(1)$ condition when time series are fractionally integrated of order lower than one leads to another issue in applied econometric analysis using the Johansen (1995) methodology. Johansen's test was developed to infer co-integration in systems composed of $I(1)$ series. As discussed earlier, the empirical researcher has difficulty distinguishing the cases $d=1$ and $d<1$ using the traditional unit root tests. In this section, the Johansen co-integration test is compared to the residual-based test in the fractional co-integration perspective.

Johansen's methodology is widespread in applied econometric analysis, so it will not be fully described here. Details on Johansen's approach can be found in Johansen $(1988,1992)$, Johansen \& Juselius (1990), Banerjee et al. (2003), Hamilton (1994), and in many other references. In order to apply Johansen's test to fractional co-integrated systems similar to those simulated in the previous section, we followed these steps: (i) we first simulated the bivariate fractionally co-integrated systems using the same algorithm used earlier in Section 4; (ii) we choose the orders of the VARs by applying the HanannQuinn (HQ) statistic minimization criteria and estimated the VARs using Ordinary Least Squares (OLS) following Lutkepohl (1990); (iv) we applied the Johansen test using the maximum eigenvalue statistic at a $5 \%$ significance level; (v) and finally a vector containing three possible results was created: null, incomplete or full rank. The relative number of incomplete-rank $(r=1)$ results reveal the percentage of positive co-integration results.

Table 5 shows the simulation results and Figure 2 shows the comparative efficiency of the ADF residual-based test and Johansen's test for small and large series. For both small and large series, the residual-based test was superior. Surprisingly, for large series the superiority of the ADF-based test was even higher on the $0.6 \leq d \leq 0.8$ interval. For $d=1$, that is, for the non cointegrated cases, the results of Johansen's test are slightly better than those of the ADF test.
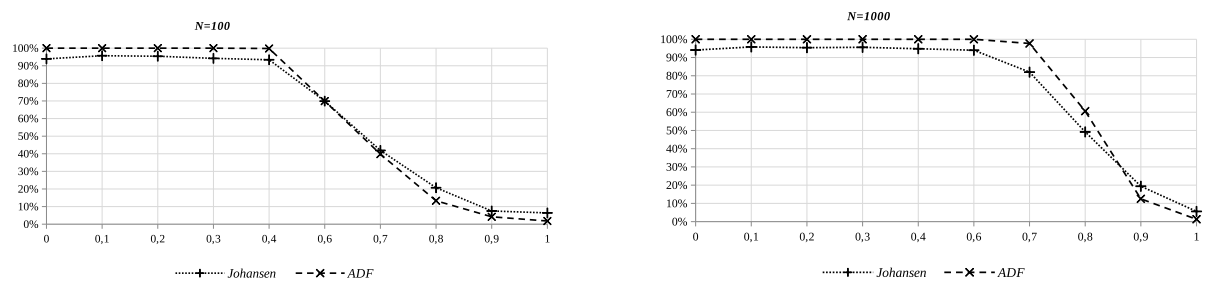

Figure 2: Comparative Percentage of Non Rejections of Co-Integration Based on Johansen and ADF Methods (5\% Significance Level)

\section{Conclusion}

This study assessed problems that frequently arise in empirical time series econometric analysis. One of the reasons for interest in the power of unit 
Table 5: Percentage of Null, Incomplete and Full Rank of Johansen's Test

\begin{tabular}{ccccccccccccc}
\hline$d$ & \multicolumn{3}{c}{$N=100$} & \multicolumn{3}{c}{$N=200$} & \multicolumn{3}{c}{$N=300$} & \multicolumn{3}{c}{$N=1000$} \\
\hline & $\pi=0$ & $\pi=1$ & $\pi=2$ & $\pi=0$ & $\pi=1$ & $\pi=2$ & $\pi=0$ & $\pi=1$ & $\pi=2$ & $\pi=0$ & $\pi=1$ & $\pi=2$ \\
\hline 0.0 & 0.0000 & 0.9390 & 0.0610 & 0.0000 & 0.9500 & 0.0500 & 0.0000 & $\mathbf{0 . 9 4 5 0}$ & 0.0550 & 0.0000 & $\mathbf{0 . 9 4 1 0}$ & 0.0590 \\
0.1 & 0.0010 & $\mathbf{0 . 9 5 7 0}$ & 0.0420 & 0.0000 & $\mathbf{0 . 9 4 9 0}$ & 0.0510 & 0.0000 & $\mathbf{0 . 9 4 7 0}$ & 0.0530 & 0.0000 & $\mathbf{0 . 9 5 8 0}$ & 0.0420 \\
0.2 & 0.0020 & $\mathbf{0 . 9 5 4 0}$ & 0.0440 & 0.0000 & $\mathbf{0 . 9 4 2 0}$ & 0.0580 & 0.0000 & $\mathbf{0 . 9 4 9 0}$ & 0.0510 & 0.0000 & $\mathbf{0 . 9 5 4 0}$ & 0.0460 \\
0.3 & 0.0070 & $\mathbf{0 . 9 4 2 0}$ & 0.0510 & 0.0010 & $\mathbf{0 . 9 5 4 0}$ & 0.0450 & 0.0000 & $\mathbf{0 . 9 5 0 0}$ & 0.0500 & 0.0000 & $\mathbf{0 . 9 5 6 0}$ & 0.0440 \\
0.4 & 0.0280 & $\mathbf{0 . 9 3 4 0}$ & 0.0380 & 0.0050 & $\mathbf{0 . 9 3 4 0}$ & 0.0610 & 0.0000 & $\mathbf{0 . 9 4 5 0}$ & 0.0550 & 0.0000 & $\mathbf{0 . 9 4 8 0}$ & 0.0520 \\
0.6 & 0.2790 & $\mathbf{0 . 6 9 9 0}$ & 0.0220 & 0.1500 & $\mathbf{0 . 8 1 8 0}$ & 0.0320 & 0.0890 & $\mathbf{0 . 8 7 3 0}$ & 0.0380 & 0.0100 & $\mathbf{0 . 9 4 0 0}$ & 0.0500 \\
0.7 & 0.5580 & $\mathbf{0 . 4 1 9 0}$ & 0.0230 & 0.3420 & $\mathbf{0 . 6 3 2 0}$ & 0.0260 & 0.2840 & $\mathbf{0 . 6 8 9 0}$ & 0.0270 & 0.1430 & $\mathbf{0 . 8 2 0 0}$ & 0.0370 \\
0.8 & 0.7850 & $\mathbf{0 . 2 0 7 0}$ & 0.0080 & 0.6610 & $\mathbf{0 . 3 3 3 0}$ & 0.0060 & 0.5890 & $\mathbf{0 . 3 9 5 0}$ & 0.0160 & 0.4960 & $\mathbf{0 . 4 9 2 0}$ & 0.0120 \\
0.9 & 0.9220 & $\mathbf{0 . 0 7 5 0}$ & 0.0030 & 0.8740 & $\mathbf{0 . 1 2 1 0}$ & 0.0050 & 0.8730 & $\mathbf{0 . 1 2 2 0}$ & 0.0050 & 0.7990 & $\mathbf{0 . 1 9 4 0}$ & 0.0070 \\
1.0 & 0.9330 & $\mathbf{0 . 0 6 4 0}$ & 0.0030 & 0.9400 & $\mathbf{0 . 0 5 8 0}$ & 0.0020 & 0.9330 & $\mathbf{0 . 0 6 6 0}$ & 0.0010 & 0.9440 & $\mathbf{0 . 0 5 6 0}$ & 0.0000 \\
\hline
\end{tabular}


root tests is the induction of over-differentiation. Given the popularity of unit root tests in econometric studies, we evaluated the power of these tests in a fractional integration approach.

Our results show that the ADF, DF-GLS and ERS tests, individually, have low power to distinguish the null hypothesis $H_{0}: d=1$ against $H_{a}: 0 \leq d<$ $1 / 2$ in small sample series. Similarly, the KPSS test has low power to reject $H_{0}: d=0$ when $H_{a}: 0 \leq d<1$ in small sample series. For large sample series, we have shown that one may use the ADF and KPSS tests together to get better results in identifying the stationary and nonstationary mean-reversion conditions. This study also shows that when $1 / 2 \leq d<1$ the ADF test has low power even with large sample series.

Since ADF is the most used unit root test in residual-based co-integration analysis, its low power can induce low power in co-integration analysis. We provided Monte Carlo evidence of this, based on the ADF and PP tests and using the Phillips e Ouliaris adjusted distributions. Particularly in this case, the results of the simulation showed that the improper use of these tests in detecting the nonstationary mean-reversion condition, especially on the interval $0.7 \leq d<1$, is the source of the low power of residual-based co-integration tests. For the asymptotic stationary interval, $0 \leq d<1 / 2$, these tests gave satisfactory results under certain conditions even for small sample series. The co-integration analysis in fractional orders based on the ADF test had better results than that based on the PP test.

Finally, a specific comparison of Johansen's co-integration tests and ADF residual-based co-integration tests was made using bivariate fractionally cointegrated systems. Following the maximum eigenvalue statistic for Johansen's test, our results indicate that the ADF residual-based test has better results for both small and large series.

\section{Bibliography}

Baillie, R. \& Bollerslev, T. (1994), 'Cointegration, fractional cointegration, and exchange rate dynamics', Journal of Finance 69, 737-745.

Ball, L. M. \& Mankiw, N. G. (2002), 'The nairu in theory and practice', Journal of Economic Perspectives 16, 115-136.

Banerjee, A., Dolado, J., Galbraith, J. W. \& Hendry, D. F. (2003), 'Cointegration, error correction, and the econometric analysis of non-stationary data', Advanced Texts in Econometrics .

Beran, J. (1994), Statistics for Long-Memory Processes, Chapman \& Hall.

Blanchard, O. I. J. \& Summers, L. (1986), Hysteresis and the european unemployment problem. Working paper No. 1950. National Bureau of Economic Research.

Campbell, J. Y. \& Mankiw, N. (1987a), 'Are output fluctuations transitory', Quarterly Journal of Economics 102(857-880).

Campbell, J. Y. \& Mankiw, N. (1987b), 'Permanent and transitory components in macroeconomic fluctuations', American Economic Review 77, 111117. 
Caporale, G. M. \& Gil-Alana, L. A. (2004), 'Fractional cointegration and tests of present value models', Review of Financial Economics 13, 245-258.

Cheung, Y. \& Lai, K. S. (1993), 'Fractional cointegration analysis of purchasing power parity.', Journal of Business E Economic Statistics 11(1), 103-112.

Dickey, D. \& Fuller, W. (1981), 'Likelihood ratio statistics for autorregressive time series with unit root', Econometrica 49, 1057-1072.

Diebold, F. X. \& Rudebusch, G. D. (1991), 'On the power of dickey-fuller tests against fractional alternatives', Economics Letters 35, 155-160.

Elliot, G., Rothenberg, T. J. \& Stock, J. H. (1996), 'Efficient tests for an autorregressive time series with a unit root', Econometrica .

Engle, R. F. \& Granger, C. W. J. (1987), 'Co-integration and error correction: Representation, estimation, and testing', Econometrica 55, 251-276.

Fava, V. L. \& Alves, D. C. O. (1998), 'Longa persistência nas taxas de inflação', Revista de Econometria 18, 245-264.

Figueiredo, E. A. \& Marques, A. M. (2011), 'Inflação inercial sob mudanças de regime: Análise a partir de um modelo ms-arfima, 1944-2009', Economia Aplicada 15, 443-457.

Franz, W. (1990), 'Hysteresis in economic relationships: An overview', Empircal Economics 15, 109-125.

Gil-Alana, L. A. \& Henry, S. G. B. (2003), 'Fractional integration and the dynamics of uk unemployment.', Oxford Bulletin of Economics and Statistics 65(2), 221-239.

Gocke, M. (2002), 'arious concepts of hysteresis applied in economics.', Journal of Economic Surveys 15, 167-188.

Gomes, F. A. R. \& Gomes da Silva, C. (2009), 'Hysteresis vs nairu and convergence vs divergence: The behavior of regional unemployment rates in brazil.', The Quarterly Review of Economics and Finance 49, 308-322.

Granger, C. W. J. (1966), 'The typical spectral shape of an economic variable', Econometrica 34, 150-161.

Granger, C. W. J. \& Joyeux, R. (1980), 'An introduction to long-memory time series models and fractional differencing', Journal of Time Series Analysis 1, 15-29.

Hamilton, J. D. (1994), Time Series Analysis, Princeton University Press, Princeton.

Hassler, U. \& Wolters, J. (1994), 'On the power of unit root tests against fractional alternatives', Economics Letters 45, 1-5.

Hosking, J. R. M. (1981), 'Fractional differencing', Biometrika 68, 165-176.

Johansen, S. (1988), 'Statistical analysis of cointegration vectors', Journal of Economic Dynamics and Control 12, 231-254. 
Johansen, S. (1992), 'Cointegration in partial systems and the efficiency of single-equation analysis', Journal of Econometrics 52, 389-402.

Johansen, S. (1995), 'Likelihood based inference in cointegrated vector error correction models', Oxford University Press .

Johansen, S. \& Juselius, K. (1990), 'Maximum likelihood estimation and inference on cointegration - with applications to the demand for money', Oxford Bulletin of Economics and Statistics 52, 169-210.

Kramer, W. (1998), 'Fractional integration and the augmented dickey-fuller test', Economics Letters 61, 269-272.

Kramer, W. \& Marmol, F. (2004), 'The power of residual-based tests for cointegration when residuals are fractionally integrated', Economics Letters 82, 63-69.

Lee, D. \& Schmidt, P. (1996), 'On the power of kpss tests of stationary against fractionally integrated alternatives', Journal of Econometrics 73, 285-302.

Lutkepohl, H. (1990), Introduction to Multiple Time Series Analysis, SpringerVerlag.

MacKinnon, J. G. (1996), 'Numerical distribution functions for unit root and cointegration tests', Journal of Applied Econometrics 11, 601-618.

Marques, G. O. L. C. \& Fava, V. L. (2011), 'Persistência e memória longa sazonal na série de desemprego da região metropolitana de são paulo', Economia Aplicada 15, 177-198.

Nelson, C. \& Plosser, C. (1982), 'Trends and random-walks in macroeconomic time-series - some evidence and implications', Journal of Monetary Economics 20, 139-162.

Ng, S. \& Perron, P. (1995), 'Unit root tests in arma models with datadependent methods for the selection of the truncation lag', Journal of the American Statistical Association 90, 268-281.

Phillips, P. C. B. \& Ouliaris, S. (1990), 'Asymptotic properties of residual based tests for cointegration', Econometrica 58, 73-93.

Reisen, V. A., Cribari-Neto, F. \& Jensen, M. (2003), 'Long memory inflationary dynamics: The case of brazil', Studies in Nonlinear Dynamics and Econometrics 7.

Shimotsu, K. (2010), 'Exact local whittle estimation of fractional integration with unknown mean and time trend', Econometric Theory 26(2), 501-540.

Sowell, F. (1990), 'The fractional unit root distribution', Econometrica 58, 495-505.

Zivot, E. \& Wang, J. (2006), Modeling Financial Time Series with S-Plus, Springer Science + Business Media, Inc, New York. 